Original Article

\title{
Knowledge and Awareness regarding Emergency Colour Codes among Resident Doctors and Nursing Staffs of Tertiary Care Facility of District Etawah
}

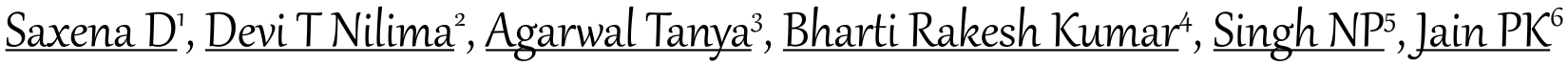 \\ 1,2,3,4 MD Post Graduate, ${ }^{5}$ Professor, ${ }^{6}$ Professor and Head of Department, Department of Community Medicine, UPUMS, Saifai, \\ Etawah, Uttar Pradesh, India.
}

DOI: https://doi.org/10.24321/2455.9199.202109

\section{I $\quad \mathbf{N} \quad \mathbf{F} \quad \mathbf{O}$}

\section{Corresponding Author:}

Saxena D, Department of Community Medicine, UPUMS, Saifai, Etawah, Uttar Pradesh, India.

E-mail Id:

drdeepanshi01@gmail.com

Orcid Id:

https://orcid.org/0000-0001-8519-2694

How to cite this article:

Saxena D, Devi TN, Agarwal T, Kumar BR, Singh NP, Jain PK. Knowledge and Awareness regarding Emergency Colour Codes among Resident Doctors and Nursing Staffs of Tertiary Care Facility of District Etawah. Int J HealthCare Edu \& Med Inform. 2021;8(1):12-18.

Date of Submission: 2021-02-02

Date of Acceptance: 2021-03-20

\section{$\begin{array}{llllllll}\mathbf{A} & \mathbf{B} & \mathbf{S} & \mathbf{T} & \mathbf{R} & \mathbf{A} & \mathbf{C} & \mathbf{T}\end{array}$}

Background: Emergency codes are comprehensive, nationwide, systematic approach to incident management, includes the command and coordination of incidents, resource management, and information management. Therefore, it is important for all residents, doctors and staff to be aware and have knowledge about it.

Aims: 1) To assess the knowledge and awareness about emergency colour codes among resident doctors and nursing staffs of tertiary care health centre. 2) To find out the training status of Advanced Cardiac Life Support and Basic Life Support among resident doctors and nursing staffs Methods and Material: A cross sectional study was conducted on all the resident doctors and the nursing staffs in UPUMS Saifai, Etawah. A pre-designed and pre-tested semi-structured questionnaire was used to get the desired information. The questions were pertaining to knowledge and awareness of emergency codes, ACLS, BLS and training regarding to it.

Data were entered in excel sheet and were analysed by using IBM SPSS version 25. Descriptive statistics was calculated for quantitative variables. Chi-square and Fischer-exact test was used for analysis of categorical variables. P value less than 0.05 was taken statistically significant.

Results: Out of 120 participants, 60\% (72/120) were resident doctors and $40 \%$ (48/120) were nursing staffs. Most of the resident doctors (47/ 72) were trained in Basic Life Support as compared to Advanced Cardiac Life Support.

Conclusions: Knowledge and awareness regarding emergency colour codes was very poor among resident doctors and nursing staffs and also training was not done in BLS and ACLS.

Keywords: Emergency Color Codes, National Incident Management System, ACLS, BLS 


\section{Introduction}

Life threatening situations can strike at any moment in any place, and to anyone. The doctor is ultimately responsible for effectively managing the emergency scenario. The inability to react with medical emergencies due to lack of training can have disastrous results and possibly the legal ramifications. ${ }^{1,2}$ Therefore, the healthcare providers must be well prepared to handle medical emergencies. The hospitals must be prepared with full list of drugs and equipment to deal efficiently and effectively with different emergencies.

To accomplish this several countries have standardised their hospital emergency codes to improve their ability. The emergency codes were created to alert medical staff to a dangerous situation while avoiding upsetting patients and visitors. ${ }^{1,4}$ When a code is called a pre-determined group of physicians, nurses and other medical staff react quickly and effectively due to their training in the same. To facilitate code uniformity the committee developed a standardized set of uniform codes and guidelines that can be adopted by all healthcare facilities. ${ }^{3-5}$ To mention a few standardized code names are Red for fire, Blue for Cardiac arrest, Black for Bomb, Pink for infant abduction, Gray for Security personnel needed, Orange for a hazardous material spill/ release and Green for Mass casuality/ Natural disaster. These are core of the principles of National Incident Management System. ${ }^{6-9}$

Along with this, the Basic Life Support and Advanced Cardiac Life Support are the medical procedures and the skills which are there to save the victim from the lifethreatening emergencies until the medical care is provided at the hospital. ${ }^{10-13}$ Creating awareness and educating nursing staff along with resident doctors is very essential to prevent the delay in providing the emergency care. Owing to the fact that nursing staff frequently become first responders in the hospital to cardiac arrest. Thus, successful resuscitation is a reflection of their skill and knowledge. BLS procedure includes cardiopulmonary resuscitation in (CPR), bleeding control, artificial ventilation and basic airway management. ${ }^{15-17}$

BLS and ACLS training has been routinely recommended training procedure for all healthcare professionals. However, these trainings are not routinely practice in developing countries like India. Hence, the present study was conducted with the aim of assessing the knowledge and awareness regarding emergency colour codes, BLS and ACLS among resident doctors and nursing staff and the prospective of introducing these skills into regular curriculum.

\section{Subjects and Methods \\ Study Design and Setting}

This cross-sectional study was conducted at Uttar Pradesh University of Medical Sciences, Saifai, Uttar Pradesh, India.

\section{Study Duration}

The study was conducted for three months duration i.e., July to September 2019.

\section{Study Participants}

The study participants were the Post Graduate resident doctors and nursing staff of all departments of our university.

\section{Sampling Plan}

The study planned to include all the Post Graduate resident doctors and nursing staff of all departments purposively.

\section{Study Tool}

The questionnaire was designed in a way that it could assess the theoretical and practical knowledge of the participant to the emergency codes and training status of BLS/CPR, and ACLS and their previous experience and exposure to it. The pilot study was conducted and the necessary corrections made accordingly.

The questionnaire consisted of four sections. First section was on sociodemographic profile, second of awareness regarding emergency color codes and its management, third of Basic Life Support and fourth section consisted of questions related to Advanced Cardiac Life Support. In second section, questions were of awareness, the meaning of color codes, team members dedicated to particular code, mock drill, emergency responding protocols and the training status. The questions regarding Basic Life Support consisted of the Cardiopulmonary Resuscitation (CPR) steps, ever performed the resuscitation, reasons for unwillingness in performing CPR, the ratio of chest compression and the training status. The questions of fourth section consisted of usage of Automatic External Defibrillator, emergency drugs, their dosage, routes of administration and the training status.

\section{Methodology and Data Collection}

The data was collected during the first two months of study period. Informed consent of those who were willing to participate in the study was taken. Those who were willing to participate and gave their consent were included in the study. Those who were not on duty due to any reason (sick leave, casual leaves, maternity leave and absentees) were not included. Those who participated in pilot study were also excluded. The authors visited all the departments and interviewed the residents and nursing staffs during three shifts i.e., morning, evening and night. In the third month of study duration the collected data in the questionnaire was entered in the excel sheet after coding for analysis.

\section{Ethical Approval}

The study proposal was approved by the Institutional Ethical Committee. Before the start of the study, the permission to carry out the study was obtained from the Dean (Medical) and Nursing Superintendent. 


\section{Statistical Analysis}

After evaluating the individual answer sheets, the scores were segregated and compared between the resident doctors and nursing staffs. A mean score of knowledge and awareness was taken as 'average' and below that was considered as 'poor' and above that as 'good'. Data were analysed by using IBM SPSS version 25.0. Descriptive statistics was calculated for quantitative variables. Chi-square and Fischerexact test was used for analysis of categorical variables. $\mathrm{P}$ value less than 0.05 at $95 \%$ Confidence interval was taken statistically significant. The conclusions were drawn based on the results of the analysis.

\section{Results}

\section{Socio-Demographic Characteristics of the Study Subjects}

A total of 120 resident doctors and nursing staff participated in the study. Of 120 responders, $72(60 \%)$ were resident doctor and $48(40 \%)$ Nursing Staff. The proportion of males $78(65 \%)$ was higher than females $42(35 \%)$. The age of the participants $(n=120)$ ranged from 25 to 42 years (Table 1$)$.

Table I.Sociodemographic Profile

$(n=120)$

\begin{tabular}{|c|c|c|c|}
\hline S. No. & Variables & Categories & Frequency (\%) \\
\hline \multirow{2}{*}{1.} & \multirow{2}{*}{ Gender } & Male & $78(65)$ \\
\cline { 3 - 4 } & \multirow{2}{*}{2.} & Female & $42(35)$ \\
\hline \multirow{2}{*}{$\begin{array}{c}\text { Age (in } \\
\text { years) }\end{array}$} & $25-30$ & $88(73.9)$ \\
\cline { 3 - 4 } & & $31-35$ & $22(18.5)$ \\
\hline \multirow{2}{*}{3.} & \multirow{2}{*}{ Occupation } & $\begin{array}{c}\text { Resident } \\
\text { Doctor }\end{array}$ & $10(7.6)$ \\
\cline { 3 - 4 } & & Nursing Staff & 72(60) \\
\hline
\end{tabular}

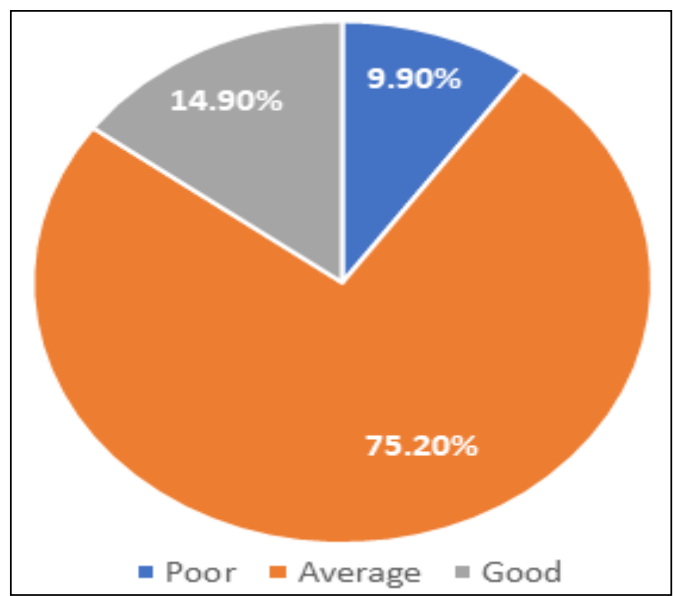

Figure I.Pie Chart Depicting Proportion of Study Participants for Knowledge and awareness Score Categorisation regarding Emergency Colour Codes among Study Participants $(n=120)$

\section{Overall Scores of Knowledge and Awareness}

The mean score of all participants was $11.71 \pm 2.72$ SD with a score range of $3-16$. The participants $(12,9.9 \%)$ below mean score were considered having poor knowledge. Those $(91,75.2 \%)$ having mean as score were considered having average knowledge. The participants $(18,14.9 \%)$ having scores greater than mean were considered as having good knowledge (Figure 1).

\section{Knowledge regarding Emergency Color Code}

In the section of knowledge (Table 2 ) regarding emergency color code, maximum $(53,75.7 \%)$ resident doctors and nursing staff $(30,62.5 \%)$ were not having correct knowledge regarding the meaning of codes $(p=0.865$ at $95 \% \mathrm{Cl})$. Most of the resident doctors $(49,70 \%)$ and nursing staff $(33,68.7 \%)$ were having knowledge of the initial fire incident objective. There was no significant difference in knowledge of resident doctors and nursing staff for both above mentioned question ( $p=0.865$ and $p=0.936$ at $95 \% \mathrm{Cl}$ ). Most of (resident doctors $55,78.5 \%$ and nursing staff $38,79.1 \%$ ) the study participants have knowledge of extinguishing techniques using a fire extinguisher. Most of (resident doctors 65, 92.8\% and nursing staff $87.5,42 \%$ ) them were having knowledge about potential hazardous material in the hospital.

\section{Awareness regarding Emergency Color Code}

In the section of awareness (Table 3 ) regarding the emergency color code, most of the resident doctors $(49,70 \%)$ and nursing staff $(45,93.7 \%)$ were aware about team members dedicated to resuscitation team and the difference between them was not found to be statistically significant $(p=0.936$ at $95 \% \mathrm{Cl})$. The resident doctors (49, $70 \%)$ were aware more than nursing staff $(45,93.7 \%)$ about team members dedicated to resuscitation team and the difference between them was found to be statistically significant $(p=0.001$ at $95 \% \mathrm{Cl})$. Majority of the resident doctors $(46,65.7 \%)$ were aware more than nursing staff $(18,37.5 \%)$ about the guidelines being followed for the training of resuscitation team and the difference between them was found to be statistically significant ( $p=0.05$ at $95 \%$ $\mathrm{Cl})$. Regarding the awareness about various exit routes of department/ hospital and emergency, the resident doctors were aware more than nursing staff and the difference between them was found to be statistically significant $(p=0.018$ at $95 \% \mathrm{Cl}$ ). Most of (resident doctors 65, 92.8\% and nursing staff $42,87.5 \%$ ) them were aware of hazardous material spill/ release protocols.

\section{Knowledge and Awareness regarding Basic Life Support and Advanced Cardiac Life Support}

A total of $87,72.5 \%$ participants responded correctly regarding the number of chest compressions in 1 minute whereas $78,65 \%$ participants could answer the ratio of chest compressions to breaths in an adult. And 67, 55.8\% study 
participants answered correctly about the location of the chest compression and only 59, 49.1\% participants could arrange the correct sequence of resuscitation. $82,68.3 \%$ out of 120 respondents were aware that defibrillation is the most important intervention in lifesaving in CPR situations which is a good awareness prevalence percentage.

\section{Training Status of Basic Life Support and Advanced Cardiac Life Support}

For the training status of the participants in Basic Life
Support 47 (65.2\%) resident doctors and 34 (70.8\%) nursing staff answered positively. For the training status of the participants in Advanced Cardiac Life Support 25 (34.7\%) resident doctors and $26(54.1 \%)$ nursing staff were found trained.

The overall training status and the comparison of the study participants is shown in Figure 2 and Table 4. This study found no association between the scores and the training status of the participants (Table 5).

Table 2.Comparison of Responses regarding Knowledge of Emergency Colour Codes among Study Participants

$(n=120)$

\begin{tabular}{|c|c|c|c|c|c|}
\hline \multirow{2}{*}{$\begin{array}{l}\text { S. } \\
\text { No. }\end{array}$} & \multirow{2}{*}{$\begin{array}{l}\text { Knowledge regarding Emergency Colour } \\
\text { Codes }\end{array}$} & \multirow[b]{2}{*}{ Responses } & \multicolumn{2}{|c|}{ Study Subjects } & \multirow{2}{*}{$\begin{array}{l}\text { P value at } 95 \% \\
\text { confidence interval }\end{array}$} \\
\hline & & & $\begin{array}{l}\text { Resident } \\
\text { Doctors }\end{array}$ & $\begin{array}{l}\text { Nursing } \\
\text { Staff }\end{array}$ & \\
\hline \multirow{2}{*}{1.} & \multirow{2}{*}{ Knowledge about emergency colour codes } & Yes & 52 & 18 & \multirow{2}{*}{$\mathrm{p}<0.05$} \\
\hline & & No & 20 & 30 & \\
\hline \multirow{2}{*}{2.} & \multirow{2}{*}{$\begin{array}{l}\text { Knowledge about correct meaning of each } \\
\text { code }\end{array}$} & Yes & 19 & 12 & \multirow{2}{*}{$p=0.865$} \\
\hline & & No & 53 & 36 & \\
\hline \multirow[b]{2}{*}{3.} & \multirow{2}{*}{$\begin{array}{c}\text { Knowledge of any recommended fire } \\
\text { disaster management plan in your hospital } \\
\text { set up }\end{array}$} & Yes & 11 & 9 & \multirow[b]{2}{*}{$p=0.617$} \\
\hline & & No & 61 & 39 & \\
\hline \multirow{2}{*}{4.} & \multirow{2}{*}{$\begin{array}{c}\text { Knowledge of the initial fire incident } \\
\text { objective }\end{array}$} & Yes & 49 & 33 & \multirow{2}{*}{$p=0.936$} \\
\hline & & No & 23 & 15 & \\
\hline \multirow{2}{*}{5.} & \multirow{2}{*}{$\begin{array}{c}\text { Knowledge of extinguishing techniques } \\
\text { using a fire extinguisher }\end{array}$} & Yes & 55 & 38 & \multirow{2}{*}{$p=0.721$} \\
\hline & & No & 17 & 10 & \\
\hline \multirow{2}{*}{6.} & \multirow{2}{*}{$\begin{array}{c}\text { Knowledge about potential hazardous } \\
\text { material in your hospital }\end{array}$} & Yes & 65 & 42 & \multirow{2}{*}{$p=0.631$} \\
\hline & & No & 7 & 6 & \\
\hline
\end{tabular}

*Chi Square test applied

Table 3.Comparison of Responses regarding Awareness related to Emergency Colour Codes among Study Participants

$(n=120)$

\begin{tabular}{|c|c|c|c|c|c|}
\hline \multirow{2}{*}{$\begin{array}{l}\text { S. } \\
\text { No. }\end{array}$} & \multirow{2}{*}{$\begin{array}{l}\text { Awareness Status about Emergency Color } \\
\text { Codes }\end{array}$} & \multirow{2}{*}{ Responses } & \multicolumn{2}{|c|}{ Study Subjects } & \multirow{2}{*}{$\begin{array}{c}\text { p Value at } 95 \% \\
\text { Confidence } \\
\text { Interval }\end{array}$} \\
\hline & & & $\begin{array}{l}\text { Resident } \\
\text { Doctors }\end{array}$ & $\begin{array}{l}\text { Nursing } \\
\text { Staff }\end{array}$ & \\
\hline \multirow{2}{*}{1.} & \multirow{2}{*}{$\begin{array}{c}\text { Awareness about team members dedicated to } \\
\text { resuscitation team }\end{array}$} & Yes & 49 & 45 & \multirow{2}{*}{$p=0.001$} \\
\hline & & No & 23 & 3 & \\
\hline \multirow{2}{*}{2.} & \multirow{2}{*}{$\begin{array}{l}\text { Awareness about the guidelines being } \\
\text { followed for the training of resuscitation team }\end{array}$} & Yes & 46 & 18 & \multirow{2}{*}{$p=0.05$} \\
\hline & & No & 26 & 30 & \\
\hline \multirow{2}{*}{3.} & \multirow{2}{*}{ Aware of acronym R.A.C.E. } & Yes & 19 & 10 & \multirow{2}{*}{$p=0.486$} \\
\hline & & No & 53 & 38 & \\
\hline \multirow{2}{*}{4.} & \multirow{2}{*}{$\begin{array}{l}\text { Awareness about emergency operation plan } \\
\text { activation }\end{array}$} & Yes & 12 & 8 & \multirow{2}{*}{$p=1.0$} \\
\hline & & No & 60 & 40 & \\
\hline \multirow{2}{*}{5.} & \multirow{2}{*}{$\begin{array}{l}\text { Awareness about various exit routes of your } \\
\text { department/ hospital and emergency numbers }\end{array}$} & Yes & 61 & 47 & \multirow{2}{*}{$p=0.018$} \\
\hline & & No & 11 & 1 & \\
\hline
\end{tabular}




\begin{tabular}{|c|c|c|c|c|c|}
\hline \multirow{2}{*}{6.} & \multirow{2}{*}{$\begin{array}{l}\text { Aware of hazardous material spill/ release } \\
\text { protocols }\end{array}$} & Yes & 58 & 35 & \multirow{2}{*}{$p=0.326$} \\
\hline & & No & 14 & 13 & \\
\hline
\end{tabular}

*Chi Square test applied

Table 4.Comparison of Training Status of the Study Participants of Basic Life Support

(BLS) and Advanced Cardiac Life Support (ACLS)

\begin{tabular}{|c|c|c|c|c|c|}
\hline \multirow[b]{2}{*}{$\begin{array}{l}\text { S. } \\
\text { No. }\end{array}$} & \multirow[b]{2}{*}{ Training Status } & \multicolumn{3}{|c|}{ Study Participants } & \multirow{2}{*}{$\begin{array}{c}\text { P value at } 95 \% \\
\text { Confidence Interval* }\end{array}$} \\
\hline & & Responses & $\begin{array}{l}\text { Resident } \\
\text { Doctors }\end{array}$ & Nursing Staff & \\
\hline \multirow{2}{*}{1.} & \multirow{2}{*}{ Basic Life Support (BLS) } & Yes & 47 & 34 & \multirow{2}{*}{$P=0.524$} \\
\hline & & No & 25 & 14 & \\
\hline \multirow{2}{*}{2.} & \multirow{2}{*}{ Advanced Cardiac Life Support (ACLS) } & Yes & 25 & 26 & \multirow{2}{*}{$p=0.035$} \\
\hline & & No & 47 & 22 & \\
\hline
\end{tabular}

*Chi Square test applied

Table 5.Association between Training Status and Knowledge and Awareness Score of Study Participants

\begin{tabular}{|c|c|c|c|}
\hline \multirow{2}{*}{ Training Status } & \multicolumn{3}{|c|}{ Knowledge and awareness score of study participants } \\
& Poor & $\mathbf{p . 9 8}$ at 95\% CI) & Good \\
\cline { 2 - 4 } & $7(10.1 \%)$ & Average & $10(14.5 \%)$ \\
\hline Trained & $5(9.6 \%)$ & $32(75.4 \%)$ & $8(15.4 \%)$ \\
\hline Not Trained & & $39(75 \%)$ & \\
\hline
\end{tabular}

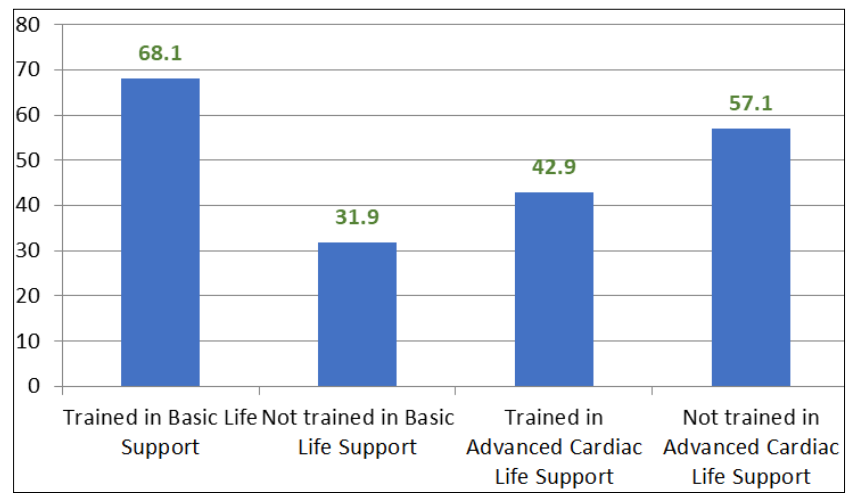

Figure 2. Bar Chart Illustrating the Training Status of Study Participants (Overall) regarding Basic Life Support and Advanced Life Support $(n=120)$

\section{Discussion}

Health professionals should have sound knowledge and awareness regarding emergency codes, BLS and ACLS. This study revealed that $9.9 \%$ (12) study participants were having poor, $75.2 \%$ (91) having average, $14.9 \%(18)$ having good knowledge and awareness regarding emergency codes regarding (Figure 1). The results of the present study were consistent with those of the study conducted by Roshana et al. ${ }^{11}$ A total of $75.2 \%$ (91) of the study participants had average knowledge. Similar results were reported by Somaraj et al. ${ }^{18}$ The overall mean score regarding the knowledge and awareness was found to be $11.71 \pm 2.72$ SD. This indicates the lack of requisite skills in emergency care, hence the need of training and retraining. The reasons attributed for lack of knowledge and awareness regarding emergency codes, BLS and ACLS in this study included lack of available professional training, busy curriculum, and lack of interest. Although no association between training status and scores was found in this study, which is contrary to the study conducted by Kumar et al. ${ }^{8}$ This may be due to difference in theoretical knowledge and practical skills. A large number $85 \%$ (102) of study participants were of the opinion that training of emergency codes, BLS and ACLS should be a part of undergraduate curriculum of both medical and nursing. As the skills deteriorated over a period of time, the students did not have confidence or have a favourable perception about CPR/ BLS. Although training improves the knowledge, the loss of skills with time highlights the need to have repeated training over a period of time. This is possible only if the training is introduced at the beginning of the curriculum rather than in the final year, which is the current practice.

Because the updating of the guidelines every 5 years, repetitive training is needed to ensure the changes. The Medical Council of India has already incorporated emergency medicine as a separate speciality. The awareness and basics of ACLS of the medical and paramedical team and BLS as the first aid will be the prime responsibility of this new emergency specialty. Educational institutions should be involved in the training of health professionals for CPR and other emergencies that can occur. CPR should be 
considered as part of curriculum. Hence, regular workshops are necessary for healthcare workers to know the practical aspects of CPR on dummies. CPR courses and workshops are usually suitable for junior and senior doctors. The limitation of the study includes the small sample size.

\section{Conclusion}

A considerable percentage of the study participants had a significant lack of knowledge pertaining to the management of medical emergencies. The focus should be placed on the training of healthcare workers with respect to emergency codes, ACLS and BLS procedures. Nothing is more valuable than life. Incorporating training in the management of medical emergencies as either a part of or as a separate course in the basic curriculum could save a life one day.

\section{References}

1. Truesdell A, Morris DP. Health Care Emergency Codes : A Guide for Code Standardization. 2009 3322(213). Available from: www.hasc.org

2. United States Department of the Interior. J Natl Med Assoc [Internet]. 1940;32(1):38. [PubMed]

3. Guidelines H. Overhead Emergency Codes. 2014;1-35. Available from: https://www.jointcommission.org/ assets/1/6/EM-2014_RECOMMENDATIONS_FOR_ HOSPITAL_EMERGENCY_CODES_FINAL_(2).pdf

4. National Incident Management System (NIMS). Found Homel Secur Law Policy. 2011;(October):279-81. https://www.fema.gov/pdf/emergency/nims/NIMS_ core.pdf

5. Commission TE, World Health Organization. Hospital emergency response checklist. World Heal Organ [Internet]. 2011;1-26. Available from: http://www. euro.who.int/_data/assets/pdf_file/0008/268766/ Hospital-emergency-response-checklist-Eng. pdf\%0Ahttp://www.euro.who.int/__data/assets/ pdf_file/0020/148214/e95978.pdf

6. Questions G. NIMS: FREQUENTLY ASKED QUESTIONS. 1-7. https://www.fema.gov/pdf/emergency/nims/ nimsfaqs.pdf

7. Al Abdulaziz A, Al Ramadan A, Al Ramadan A. Knowledge and Attitudes toward Cardiopulmonary Resuscitation and Defibrillation among Primary HealthCare Physicians in Al-Ahsa, Saudi Arabia. Int J Sci Stud. 2018;6(8):41-51. [Google Scholar]

8. Kumar H, Upadhya Ps, Ashok Ps, Chowdari Ga, Niranjan G, Dinesh B. A cross-sectional study on awareness and perception about basic life support/cardio-pulmonary resuscitation among undergraduate medical students from coastal South India. Int J Med Public Heal. 2013;3(3):146. [Google Scholar]
9. Narayan DPR, Biradar S V, Reddy MT, BK S. Assessment of knowledge and attitude about basic life support among dental interns and postgraduate students in Bangalore city, India. World J Emerg Med. 2015;6(2):118. [Google Scholar] [PubMed]

10. Pillai VS, Ramesh B, Koshy RC. Knowledge, Attitude and Practice of current Cardiopulmonary Resuscitation guidelines - a survey among nurses. J Nurs Heal Sci. 2016;5(2):9-11. [Google Scholar]

11. Roshana S, KH B, RM P, MW S. Basic life support: knowledge and attitude of medical/paramedical professionals. World J Emerg Med. 2012;3(2):141. [Google Scholar]

12. Chandrasekaran S, Kumar S, Bhat SA, Saravanakumar, Shabbir PM, Chandrasekaran Vp. Awareness of basic life support among medical, dental, nursing students and doctors. Indian J Anaesth. 2010 Jan;54(2):121-6. [PubMed] [Google Scholar]

13. Bingham AL, Sen S, Finn LA, Cawley MJ. Retention of advanced cardiac life support knowledge and skills following high-fidelity mannequin simulation training. Am J Pharm Educ. 2015;79(1):12-9. [PubMed] [Google Scholar]

14. Ashworth I, El Dali AM, ElDeib O, Altoub AA, Pasha F, Butt T. Variability of emergency color codes for critical events between hospitals in Riyadh. Ann Saudi Med. 2015;35(6):450-5. [PubMed] [Google Scholar]

15. Padilla-Elías $N$, Peña-Orellana $M$, Rivera-Gutiérrez $R$, Gónzalez-Sánchez JA, Marín Centeno HA, Alonso-Serra $\mathrm{H}$, et al. Diversity of Emergency Codes in Hospitals. Int J Clin Med. 2013;04(11):499-503. [Google Scholar]

16. Sangamesh NC, Vidya KC, Pathi J, Singh A. Awareness, attitude, and knowledge of basic life support among medical, dental, and nursing faculties and students in the university hospital. J Int Soc Prev Community Dent. Jul-Aug 2017;7(4):161-167. [PubMed] [Google Scholar]

17. Srinivasan R, Krishnan SG, Bhojaraja S, Srinivasan M. Basic life support skills and health emergency preparedness among school teachers in India: a questionnaire-based study in an urban population. Int J Community Med Public Heal. 2019;6(9):3780. [Google Scholar]

18. Somaraj V, Shenoy RP, Panchmal GS, Jodalli PS, Sonde L, Karkal R. Knowledge, attitude and anxiety pertaining to basic life support and medical emergencies among dental interns in Mangalore City, India. World J Emerg Med. 2017;8(2):131. [PubMed] [Google Scholar]

19. Mukherji A, Singh M, Nahar P, Bhuvaneshwari S, Goel S, Mathur H. Competence of handling medical emergencies among dental graduates and postgraduate students - A cross-sectional questionnaire 
study. J Indian Acad Oral Med Radiol. 2019;31(2):107. [Google Scholar]

20. Al Harbi N, Afifi A, Alateeq $M$, Tourkmani A, Alharbi T, Albattal S. Awareness of basic life support and cardiopulmonary resuscitation among female secondary school students in government schools in Riyadh city, KSA. J Fam Med Prim care. 2018;7(6):1493. [Pubmed] [Google Scholar] 